\section{Processing-induced Tooth Displacement and Occlusal Changes in Complete Dentures - An Overview}

\section{Abstract}

Objectives: The aim of this overview is to discuss about

$>$ The various factors and variables involved in complete denture processing that can contribute to tooth displacement in complete dentures.

$>$ The precautions to be taken to minimize it.

Materials and methods: A PubMed search was conducted ending in June 2015 using search terms; artificial tooth movement, tooth displacement, complete dentures, processing. Literature search was completed by hand search accessing the references cited in all the selected publications.

Results: The literature search yielded 114 papers in PubMed. Twenty five articles were selected and cross references of these articles were checked. All the English language publications which met the defined objectives were included for the overview.

Conclusion: From the present overview, we can conclude that the defined processing procedures must be carefully followed by dental clinicians, technicians and students to avoid occlusal errors in complete dentures due to linear and vertical tooth movement. Each step in the processing procedure must be meticulously carried out and the suggested preventive measures can be followed to ensure predictable treatment outcome.

Keywords: Tooth displacement; Complete dentures; Compression-molded; Processing

\section{Komal Ladha and Bhawana Tiwari}

\section{Department of Prosthodontics, ESIC Dental College and Hospital, Rohini, New Delhi,} India

\section{Corresponding author: Komal Ladha}

\section{” komalladha@yahoo.co.in}

Associate Professor, Department of Prosthodontics, ESIC Dental College and Hospital, Rohini, New Delhi-110 089, India.

Tel: +919910036215

Citation: Ladha K, Tiwari B. Processing-induced Tooth Displacement and Occlusal Changes in Complete Dentures - An Overview. Periodon Prosthodon. 2015, 1:1.

Received: December 01, 2015; Accepted: December 10, 2015; Published: December 12,2015

\section{Introduction}

Predictable treatment outcomes with complete dentures in edentulous patients involves a complex array of different factors. Among the most important factors, occlusal stability has an important role and is obtained by achieving maximum number of tooth contacts during the artificial teeth positioning in wax. However, the movement of teeth during processing of complete dentures disturbs the harmonious occlusal scheme established at the final wax try-in stage [1]. There are two main factors responsible for occlusal discrepancies in the processed dentures: A) change in the relationship of a tooth / teeth to the master cast during processing as a result of investing procedure, careless packing of acrylic resins in the mold cavity, or improper flask closure and B) warpage of the denture base due to release of inherent strains when the denture is separated from the cast [2].

The combination of polymerization shrinkage, thermal contraction during flask cooling and strain accompanying stress release during deflasking can result in denture base distortion and displacement of artificial teeth $[3,4]$ leading to alterations in occlusal contacts, vertical dimension of occlusion and decrease in stability and retention of dentures [5-7]. Teeth displacement can occur in any direction; antero-posterior, transverse or vertical. It can also occur due to several other factors such as base thickness $[8,9]$, palatal form $[1,10]$, flask closure $[5,11]$, investing media and procedure [12-19], polymerization techniques [15], flask cooling method $[11,20]$, post-pressing time $[5,21]$, water storage $[20,22]$, monomer-polymer ratio [23] and wax instability [24]. 
Therefore, the problem of occlusal imbalance resulting from tooth movements during the laboratory processing of complete dentures by compression molding is a real and bothersome one. These tooth movements make occlusal spot grinding necessary prior to the use of the prosthesis by the patient. Gross occlusal discrepancies might even require remake of either one or both the complete dentures.

The present article aims to highlight and discuss the variables causing tooth movement in complete dentures fabricated with heat-cured acrylic resin using the conventional compression molding technique.

\section{Materials and Methods}

A bibliographic search was carried out using PubMed until June, 2015. The search terms used were: artificial tooth movement, tooth displacement, complete dentures, processing. The literature search was completed by hand search accessing the references cited in all identified publications. Because of the paucity of literature review in this field, no specific criteria were established.

The articles were selected and assessed on the basis of various factors and variables involved in complete denture processing that could contribute to tooth displacement. These included, steps from wax-up till finishing; use of different investing materials, methods and armamentarium; and properties of the materials used.

\section{Results}

Literature search using the specified terms yielded 114 papers in PubMed. Out of these, 25 articles that were relevant to the present overview were selected. Cross references of these articles were checked and all the English language publications which met the defined objectives were included. The results are summarized in Table 1. The various factors are discussed below.

\section{Tooth displacement during different stages of denture processing}

Tooth movement in waxed trial dentures: Artificial teeth arranged meticulously at the wax try-in stage might move before being invested for processing. Baseplate wax used for teeth arrangement is amorphous in nature and its manipulation during articulation of teeth induces stresses. Waxes are sensitive to temperature changes and shrink considerably upon cooling, inducing more stresses. These stresses and the resulting strains cause tooth movement. This movement will disturb the planned denture occlusion.

It has been suggested that a suitable synthetic wax with constant physical properties and a spray of thin plastic film capable of instantly holding the teeth in desired positions in wax will be of great help in preventing tooth movement [24]. Also the waxed trial dentures must be flasked immediately to avoid any changes due to wax expansion or contraction.

\section{Flasking and type of investing material}

There is evidence to indicate that vertical shifting of teeth occurs during investing. Expansion of and heat liberated by the setting investing material (second pour) is sufficient to move the teeth in wax [25]. Grant had shown tooth movements of 0.02 to 0.05 $\mathrm{mm}$ resulting from this expansion [13]. He also suggested that distortion of the original gypsum cast, resulting from pressures developed during processing, induced further errors in occlusion [26]. Tooth displacement could however be decreased because the plaster set expansion will compensate partially for the polymerization shrinkage of acrylic resin [12]

Many studies have evaluated the relationship between the investing material and the vertical occlusal changes that occur during processing [14-18]. The materials studied were; laboratory silicone, used as a layer to cover all the artificial teeth and an all gypsum investing technique. Except Marcroft, [14] who reported occlusal accuracy obtained with a layered silicone rubber mold to be markedly superior to that of the usual method of processing in split molds made of gypsum products, all the others did not report any significant difference in vertical tooth movement between the two materials [15-18].

Different results have been obtained regarding the influence of silicone on linear displacement of teeth. Shibayama et al. [19] and Boscato et al. [22] observed that use of a silicone layer resulted in the least positional changes of artificial teeth. Mainieri [15] had reported that the horizontal movement of teeth was more lingual in the silicone technique. Lechner however, reported that investing material does not influence linear distances (anteroposterior) as long as artificial teeth can be kept in position by the virtue of the existence of mesio-distal contacts [27].

It is well known that use of stone matrix will help prevent shifting of the teeth during flasking and facilitates easy separation of the investment from the finished denture. Close adaptation of the investing material by the "brush-on" method is more important than the hardness of the material used [12].

\section{Packing}

Monomer-polymer ratio: Another factor that can cause dimensional change in resin is the monomer-polymer ratio. Higher polymer content can yield a dry mixture, resulting in a material mass with disabilities to convert monomer into polymer. Alternately, excess monomer content may produce higher contraction due to excessive polymerization. It was hypothesized that changes in monomer-polymer ratio from that recommended by the manufacturer might cause linear displacement of teeth. However, the results did not report any change [23].

Packing of the mix: Careless packing of acrylic resins or excess resin in the mold cavity at the final closure can

cause tooth displacement [28]. An increase in vertical dimension of the dentures results from an acrylic resin "flash" between the two halves of the mold or from a failure to close the flask completely. The amount of tooth movement is equivalent to the thickness of the resin flash [25].

However if the flask is closed too rapidly to permit the resin to flow into all spaces, unequal pressure will be exerted and tooth displacement might occur $[12,29]$. 
Table 1 Variables influencing tooth movement during complete denture processing.

\begin{tabular}{|c|c|c|c|c|}
\hline S No & Variables & Linear movement & Vertical movement & Precautions/favorable preventive measures \\
\hline 1. & $\begin{array}{l}\text { Wax-up of trial } \\
\text { dentures [24] }\end{array}$ & & Causes vertical changes & $\begin{array}{l}\text { Use of a suitable wax with constant physical } \\
\text { properties. }\end{array}$ \\
\hline 2. & Investing [25] & & Causes vertical changes & Use of stone matrix/coring \\
\hline 3. & $\begin{array}{l}\text { Investing material } \\
{[14-18]}\end{array}$ & No linear or & Vertical changes & $\begin{array}{l}\text { Use of silicone layer facilitates ease of } \\
\text { deflasking and provides cleaner dentures. }\end{array}$ \\
\hline 4. & $\begin{array}{l}\text { Monomer-polymer } \\
\text { ratio } \\
{[23]}\end{array}$ & No linear changes & & $\begin{array}{l}\text { Monomer-polymer ratio as per } \\
\text { manufacturer's recommendations. }\end{array}$ \\
\hline 5. & $\begin{array}{l}\text { Packing of mix } \\
{[28]}\end{array}$ & & $\begin{array}{l}\text { Significant influence on } \\
\text { vertical changes due to } \\
\text { careless packing }\end{array}$ & Avoid excess resin at final flask closure \\
\hline 6. & $\begin{array}{l}\text { Flask closure } \\
\text { method [33] }\end{array}$ & $\begin{array}{l}\text { No significant influence on } \\
\text { linear movement. }\end{array}$ & & $\begin{array}{l}\text { Avoid too rapid closure of flask. RS tension } \\
\text { system comparable with conventional } \\
\text { packing. }\end{array}$ \\
\hline 7. & $\begin{array}{l}\text { Post-pressing time } \\
{[21]}\end{array}$ & $\begin{array}{l}6 \text { hour post-pressing time had } \\
\text { no significant advantage over } \\
\text { the usual } 45 \text { mins to } 1 \text { hour of } \\
\text { bench curing. }\end{array}$ & & \\
\hline 8. & $\begin{array}{l}\text { Type of flask } \\
{[17,36]}\end{array}$ & $\begin{array}{l}\text { Bimaxillary flasks reduce } \\
\text { linear movement }\end{array}$ & and vertical tooth movement & Use of bimaxillary flasks advantageous. \\
\hline 9. & $\begin{array}{l}\text { Molding technique } \\
{[10,37-39]}\end{array}$ & & $\begin{array}{l}\text { Injection molding reduces } \\
\text { vertical and occlusal changes. }\end{array}$ & $\begin{array}{l}\text { Injection-molding technique superior to } \\
\text { compression molding. }\end{array}$ \\
\hline 10. & $\begin{array}{l}\text { Curing and } \\
\text { deflasking }[41,42]\end{array}$ & $\begin{array}{l}\text { Significant linear dimensional } \\
\text { changes. }\end{array}$ & & $\begin{array}{l}\text { Inevitable due to polymerization shrinkage } \\
\text { and stresses induced during cooling. } \\
\text { Maintain spring clamp pressure during curing. }\end{array}$ \\
\hline 11. & $\begin{array}{l}\text { Polymerization cycle } \\
{[41]}\end{array}$ & $\begin{array}{l}\text { Processing-induced malocclusion in } \\
\text { short curing } \\
\text { cycle. }\end{array}$ & & Long curing cycle recommended. \\
\hline 12. & $\begin{array}{l}\text { Flask cooling } \\
{[49]}\end{array}$ & $\begin{array}{l}\text { Significant linear dimensional } \\
\text { changes upon rapid flask } \\
\text { cooling by quenching }\end{array}$ & & $\begin{array}{l}\text { Slow cooling of the flasks recommended. } \\
\text { Bench cooling causes more shrinkage than } \\
\text { slow cooling inside the curing bath. }\end{array}$ \\
\hline
\end{tabular}




\begin{tabular}{|c|c|c|c|c|}
\hline 13. & $\begin{array}{l}\text { Bench storage } \\
{[11]}\end{array}$ & $\begin{array}{l}\text { For } 3 \text { hours after cooling in } \\
\text { curing water caused antero- } \\
\text { posterior dimensional } \\
\text { changes. }\end{array}$ & & \\
\hline 14. & $\begin{array}{l}\text { Finishing of } \\
\text { dentures [51-53] }\end{array}$ & $\begin{array}{l}\text { Significant war page and } \\
\text { dimensional changes due to } \\
\text { overheating, with } \\
\text { temperatures beyond } 100^{\circ} \mathrm{C}\end{array}$ & & Avoid overheating during finishing. \\
\hline 15. & $\begin{array}{l}\text { Water sorption } \\
{[55,20]}\end{array}$ & Insignificant linear and & Vertical dimensional changes & $\begin{array}{l}\text { Water sorption compensates partly for the } \\
\text { processing shrinkage. }\end{array}$ \\
\hline 17. & $\begin{array}{l}\text { Palatal form } \\
{[1,10]}\end{array}$ & $\begin{array}{l}\text { Both deep and shallow palatal } \\
\text { vaults are associated with } \\
\text { tooth movement and linear } \\
\text { dimensional changes. }\end{array}$ & & $\begin{array}{l}\text { Medium palatal form shows minimal tooth } \\
\text { movement. }\end{array}$ \\
\hline
\end{tabular}

Yellow: Significant; Green: Not significant

Packing method/Flask closure method: The pressure applied at the final flask closure is released when the

flask is removed from the manual or hydraulic press and placed in the spring clamp. This procedure may generate a great stress release as reported by Consani et al. [30]. A new packing method, the RS tension flask closure system, was proposed to avoid flask opening and the associated dimensional changes. In this system, the flask halves remained in contact when the flask was removed from the hydraulic press and therefore the acrylic resin was maintained under constant pressure conditions. This impeded the release of residual internal stresses from the acrylic dough before polymerization [30].

The denture bases processed with this packing system were found to be more dimensionally stable $[30,31]$. The reduction in base inaccuracies allowed the teeth to preserve their position in the dentures [2,32].

However, studies on the effect of the RS tension system on linear tooth displacement showed varied results. While one study suggested that the RS system standardized tooth displacement and reduced the magnitude of tooth movement [5] others reported a similar performance when compared with the conventional method [11,33].

Post-pressing time: A factor that may significantly affect occlusal contacts is the delay in polymerizing the

denture after the final pressing procedure [5]. A classic study reported that one reason for allowing the flask to stand for at least one hour before polymerizing is to allow the resin mass to flow into all regions of the mold and, thus, relieve the internal stress during the early stage after closure. Also, it would reduce the amount of residual monomer present in the resin dough [28].

Studies compared the influence of immediate polymerization and 6 hour post-pressing time on tooth movement. It was suggested that a delay of 6 hours before polymerization might be an important factor in controlling the magnitude of tooth movement [5]. However, no significant advantage was reported [21].

Flask type: Bimaxillary flasks (metallic and polyvinyl chloride) for conventional and microwave processing

were developed so that maxillary and mandibular dentures are processed at the same time with teeth in occlusion which helps minimize tooth displacement, saves time and maintains the occlusal vertical dimension [34,35]. Studies have shown that dentures processed in bimaxillary flasks exhibit a reduction in vertical dimensional changes and linear movement of artificial teeth when compared with those processed in conventional flasks $[17,36]$.

Molding technique: In order to minimize the increase in vertical dimension of occlusion, injection molding

technique has been recommended. Studies have reported superiority of this technique with regards to dimensional stability, vertical and occlusal changes when compared with the compression molding technique [10,37-39]. 


\section{Curing and deflasking}

Atkinson and Grant showed that greater tooth movements were seen at the polymerization stage than at the packing stage [40]. Dimensional changes in dentures due to polymerization shrinkage includes volumetric, linear and thermal shrinkage [3].

The acrylic dough shrinks about $7 \%$ by volume when it polymerizes. Linear shrinkage has a significant effect upon denture base adaptation and cuspal interdigitation. It is a result of thermal shrinkage of the heat-cured resin. Following polymerization, the cured resin must cool down to room temperature restrained by the gypsum mold. This rigid mass contracts at a different rate from that of the surrounding dental plaster. This disparity results in stresses within the resin. Additional stresses are generated due to inhibition of shrinkage of the polymer chains by the mold walls, improper heating and cooling of the flask assembly and improper handling of resins [3].

The relaxation of these stresses after removal of the processed denture from the master cast cause linear dimensional changes and alters the occlusion [41]. Also, failure to use spring clamp during curing might cause expansion of the acrylic resin and result in tooth movement.

Linear changes are determined by measuring distance between two predetermined points in the second molar regions at try-in, after processing with denture on the cast, and after removal of dentures from the cast. Woelfel et al. measured linear changes across the second molar and buccal flange areas and found that the greatest changes occurred immediately after deflasking [42].

Polymerization cycle: A classical study reported that processing dentures by long cycle in a water bath is

recommended, as it causes least dimensional changes [43]. McCartney concluded that a short curing cycle produced more processing shrinkage. Short curing cycle that included subjecting the acrylic resin denture base to boiling temperature resulted in a $25 \%$ increase in space in the posterior palatal region and a $50 \%$ increase in induced malocclusion compared with longer curing cycle and moderate temperature [41].

However, Negreiros found that both the cycles were alike as regards dimensional stability, characterizing the complexity of all the factors that interact during complete denture processing.

Flask cooling method-bench storage: It is an accepted theory that the teeth have a tendency to move towards each other because of thermal shrinkage [44]. The magnitude of dimensional change is strongly dependent on the cooling method as internal stresses developed due to thermal shrinkage are relaxed during the cooling process [45].

The cooling methods include; slow cool, that is allowing the flask to cool slowly inside the water bath for 36 hours and bench cool, that is flasks are removed from the water bath and bench cooled for 12 hours [46].

Slow cooling inside the water bath is recommended before deflasking to avoid high residual stresses generated by thermal expansion differences between the plaster mold and denture base $[3,47,48]$. Rapid cooling can induce uneven thermal contraction, and the resultant stress may be partly relieved during deflasking, thereby inducing significantly larger shrinkage and greater warpage $[49,50]$. Similar results with an increase in the molar to molar dimensional change have been shown by a study when flasks were rapidly cooled by quenching in water [49].

A study evaluated the effect of bench storage for 3 hours subsequent to cooling in curing water on tooth movement. Differences in the antero-posterior distances were observed when compared with the dentures that were cooled in curing water only. However, they did not consider the influence of subsequent storage in water [11].

Another study that evaluated the effect of water storage after flask cooling in curing bath and bench storage for 3 hours on posterior teeth movement showed no significant dimensional changes in posterior teeth distances when compared with the measurements at deflasking [20]. This may be because the shrinkage during cooling might have been compensated by expansion due to water sorption.

\section{Finishing}

Extreme warpage may occur when heat-cured dentures are finished in a manner that produces high heat [51]. The heat produced by grinding and polishing could soften the resin and allow the stresses trapped during cooling to be released. It has been found that local temperature rise causes depolymerization of the surface resin and produces sufficient surface stresses to cause warpage [52].

Grinding with arbor bands produced heat rapidly than with carbide burs. This probably occurs because the arbor bands lose its efficiency quickly as the abrasive wears off, encouraging heat build-up. Although temperature in the resin $2 \mathrm{~mm}$ from the grinding instrument never approaches glass transition temperature of resin, the temperature immediately adjacent to the cutting tool can be extremely high. Overheating even small regions may allow stress relaxation and warpage to occur [53]. However, it has been found that no significant distortion and inter-molar dimensional change occurred at temperatures below $100^{\circ} \mathrm{C}[53,54]$.

Clinicians, dental assistants, dental students and dental laboratory technicians must recognize that denture resins are sensitive to the finishing techniques and must be careful to avoid dimensional and occlusal changes.

\section{Water sorption}

The literature shows that water sorption by resin base occurs during clinical use. Skinner and Cooper stated that water sorption by acrylic denture base generally compensates for the shrinkage that occurs during processing [55]. The resulting dimensional changes may affect occlusion of the denture due to movement of the teeth. Although the vertical changes are small, it may cause discomfort to the patients $[55,56]$.

A study that evaluated the effect of water storage for up to 3 months on linear dimensional changes showed no significant differences [20]. Similar results were reported by Sykora and Sutow when dentures processed by trial-pack technique were 
immersed in water at room temperature for 1 hour, one day and one week [10].

Effect of curing cycle on water sorption showed that linear dimensional change for short-cured acrylic specimens were higher than that for long-cured specimens after 30 days [57].

A study that evaluated the effect of flask cooling methods and immersion in water on dimensional changes observed that bench-cooled dentures showed greater processing shrinkage and higher expansion upon water storage than those slowly cooled in curing bath. This higher expansion was not a result of higher water sorption, but perhaps because of the plasticizing effect of water allowing the stress to be released [46].

\section{Base thickness}

The thickness of acrylic resin dentures is believed to be a significant factor in determining the magnitude of the shrinkage that occurs during processing $[58,59]$. Sadamori et al. suggested that linear dimensional changes after deflasking were greater in thicker acrylic resin dentures and they required longer to become dimensionally stable $[9,60]$.

The effect of denture thickness on tooth movement during processing of complete dentures was studied by Jamani and Abuzar. The results showed that there were significant variations in tooth movement between thick and thin denture bases. Also, an increase in the molar-to-molar distance was found in both the thin and thick dentures but the magnitude of tooth movement was greater in thick dentures [8].

\section{Palatal form}

Tooth movement during processing and its relation to the palatal form have been studied by some authors. They have reported that a positive correlation exists between the palatal form and tooth movement before processing and after deflasking of the denture $[1,10]$.

Abuzar et al. found that, in shallow palates, the acrylic resin shrinkage occurred almost parallel to the flat palate, and after cooling and deflasking, the stress release pulled the opposing teeth together. In deep palates, thermal shrinkage occurred at an angle along the palatal slopes and the release of stress after deflasking caused the denture to be pulled away from the cast and the teeth moved buccally.

After removal of the denture from the master cast, an overall palatal movement of the teeth occurred across the arch in both shallow and deep palates, however, patients with high palates exhibited greater movement. This might be caused by immediate stress release.

After finishing and polishing, teeth had a tendency to move buccally, regardless of the palatal form. This might be due to the heat-related warpage that might have occurred during denture trimming [1].

This study used the compression molding technique and reported greater tooth movements than other studies but comparable with the results published by Sykora and Sutow who used both compression and injection-molded technique [10]. They also indicated minimal tooth movement in medium palatal forms [1].

\section{Conclusion}

Occlusal discrepancies are produced in complete dentures as a result of processing procedures, and these must be corrected before the denture insertion appointment. The processing warpage and denture base distortion that occur when the polymerized dentures are removed from the cast are the major disadvantages of acrylic resin, and these factors can modify the teeth position. Careful processing can minimize changes in planned occlusal contacts of the opposing artificial posterior teeth.

Further studies must be conducted to evaluate the effect of denture processing procedure on tooth displacement to ensure a more stable occlusal pattern, retention and functional quality of complete dentures. It is suggested that if the dentures are processed one at a time and remounted for occlusal corrections against the opposing waxed dentures, the chances for final occlusal corrections would be minimized. The dental clinicians, technicians and students must meticulously control all the steps involved in denture processing, from wax-up till finishing to ensure least dimensional changes.

\section{References}

1 Abuzar MAM, Jamani K, Abuzar M (1995) Tooth movement during processing of complete dentures and its relation to palatal form. J 
Prosthet Dent 73: 445-449.

2 Wesley RC, Henderson D, Frazier QZ, Rayson JH, Charles WE, et al. (1973) Processing changes in complete dentures: Posterior tooth contacts and pin opening. J Prosthet Dent 29: 46-54.

3 Phoenix RD (1996) Denture base resins: Technical considerations and processing techniques. In Anusavice KJ, Phillips' Science of Dental Materials. (10th edn) Philadelphia, PA, Saunders WB. pp: 237-271.

4 Anusavice KJ (2003) Phillips' Science of Dental Materials. (11th edn) Elsevier Health Sciences, Saunders. p: 832.

5 Negreiros WA, Consani RL, Mesquita MF, Mario ACS, Ivan RF (2009) Effect of Flask Closure Method and Post-Pressing Time on the Displacement of Maxillary Denture Teeth. Open Dent J 3: 21-25.

6 Lechner SK, Thomas GA (1994) Changes caused by processing complete mandibular dentures. J Prosthet Dent 72: 606-613.

7 LaBarre E, Giusti L, Pitigoi-Aron G (2007) Addressing problems in complete dentures. Compend Contin Educ Dent 28: 538-540.

8 Jamani KD, Abuzar MAM (1998) Effect of denture thickness on tooth movement during processing of complete dentures. J Oral Rehabil 25: 725-729.

9 Sadamori S, Ishii T, Hamada T (1997) Influence of thickness on the linear dimensional change, warpage, and water uptake of a denture base resin. Int J Prosthodont 10: 35-43.

10 Sykora O, Sutow EJ (1993) Posterior palatal seal adaptation: influence of processing, palate shape and immersion. J Oral Rehabil 20: 19-31.

11 Consani RLX, Domitti SS, Mesquita MF (2006) Influence of flask closure and flask cooling methods on tooth movement in maxillary dentures. J Prosthodont 15: 229-234.

12 Perlowski SA (1953) Investment changes during flasking as a factor of complete denture malocclusion. J Prosthet Dent 3: 497-499.

13 Grant AA (1962) Effect of investment procedure on tooth movement. J Prosthet Dent 12: 1053-1058.

14 Marcroft KR, Tencate RL, Hurst WW (1961) Use of a layered silicone rubber mold technique for denture processing. J Prosthet Dent 11: 657-664.

15 Mainieri ET, Boone ME, Potter RH (1980) Tooth movement and dimensional change of denture base materials using two investing methods. J Prosthet Dent. 44: 368-373.

16 Tucker KM, Freeman BJ (1971) The effect of investing material on processing changes in complete dentures. J Prosthet Dent 25: 206210.

17 Sotto-Maior BS, Jóia FA, Meloto CB, Cury AA, Rizzatti-Barbosa CM (2012) Effect of double flasking and investing methods on artificial teeth movement in complete dentures processing. Gerodontology 29: e435-e439.

18 Neto AF, Santos Sousa RL, Rizzatti-Barbosa CM (2012) The influence of double flask investing on tooth displacement in dentures processed by microwave irradiation. Gerodontology 29: e924-e929.

19 Shibayama R, Gennari Filho H, Mazaro JV, Vedovatto E, Assunção WG (2009) Effect of flasking and polymerization techniques on tooth movement in complete denture processing. J Prosthodont 18: 259264.

20 Consani RLX, Domitti SS, Mauricio T, Antonio MS (2003) Effect of bench delay after flask cooling on the posterior teeth movement in maxillary complete dentures. Cienc Odontol Bras 6: 6-10.
21 Negreiros WA, Consani RL, Verde MA (2009) The role of polymerization cycle and post-pressing time on tooth movement in complete dentures. Braz Oral Res 23: 467-472.

22 Boscato N, Consani RLX, Consani S (2005) Effect of investment material and water immersion time on tooth movement in complete denture. Eur J Prosthodont Rest Dent 13: 164-169.

23 Lopes MC, Consani RL, Mesquita MF, Alexandre CS, Consani S (2011) Effect of monomer content in the monomer-polymer ratio on complete denture teeth displacement. Braz Dent J 22: 238-244.

24 Shetty NS, Udani TM (1986) Movement of artificial teeth in waxed trial dentures. J Prosthet Dent 56: 644-648.

25 Lam RV (1965) Disorientation of the tooth to cast relationship as a result of flasking procedures. J Prosthet Dent 15: 651-661.

26 Grant AA (1963) Distortion of gypsum casts following polymerization of methyl methacrylate. J Dent Res 42: 8-17.

27 Lechner SK, Thomas GA (1994) Changes caused by processing complete mandibular dentures. J Prosthet Dent 72: 606-613.

28 Peyton FA (1950) Packing and pressing denture base resins. J Am Dent Assoc 40: 520-528.

29 Taylor PB (1941) Acrylic resins: Their manipulation. JADA 28: 375-387.

30 Consani RL, Domitti SS, Consani S (2002) Effect of a new tension system, used in acrylic resin flasking, on the dimensional stability of denture bases. J Prosthet Dent 88: 285-289.

31 Consani RL, Domitti SS, Mesquita MF (2004) Effect of packing types on the dimensional accuracy of denture base resin cured by the conventional cycle in relation to post-pressing times. Braz Dent J 15: 63-67.

32 Kyes FM (1951) Laboratory's role in successful full dentures. I Prosthet Dent 1: 196-203.

33 Negreiros WA, Consani RL, Mesquita MF (2008) Effect of the flask contention method on the displacement of maxillary denture teeth. Braz J Oral Sci 24: 1493-1496.

34 Sadan A (2004) Quintessence of Dental Technology, Quintessence Publishing Company, Chicago, Quintessence, pp: 217.

35 Rizzati-Barbosa CM, Machado C, Joia FA (2005) A method to reduce tooth movement of complete dentures during microwave irradiation processing. J Prosthet Dent 94: 301-302.

36 Rizzatti-Barbosa CM, Cunha VPP, Marchini L (2003) The influence of double flask processing in occlusal plane when a couple of dentures are processed in occlusal position. Braz J Oral Sci 2: 264-267.

37 Strohaver RA (1989) Comparison of changes in vertical dimension between compression and injection molded complete dentures. J Prosthet Dent 62: 716-718.

38 Huggett R, Zissis A, Harrison A (1992) Dimensional accuracy and stability of acrylic resin denture bases. J Prosthet Dent 68: 634-640.

39 Campos MS, Cavalcanti BN, Cunha VP (2005) Occlusal changes in complete dentures processed by pack-and-press and injectionpressing techniques. Eur J Prosthodont Rest Dent 13: 78-80.

40 Atkinson HF, Grant AA (1962) An investigation into tooth movement during the packing and polymerizing of acrylic resin denture base materials. Aust Dent J 7: 101-108.

41 McCartney JW (1984) Flange adaptation discrepancy, palatal base distortion, and induced malocclusion caused by processing acrylic resin maxillary complete dentures. J Prosthet Dent 52: 545-553. 
42 Woelfel JB, Paffenbarger GC, Sweeney WT (1960) Dimensional changes occurring in dentures during processing. JADA 61: 413-430.

43 Stanford JW, Paffenbarger GC (1982) Processing denture base resins: heat-cure type. JADA 1956 53: 72-73.

44 Phillips RW (1982) Skinner's Science of Dental Materials. (8th edn) Philadelphia and WB Saunders Co. p: 646.

45 McCabe JF, Wilson HJ (1980) The use of differential scanning calorimetry for the evaluation of dental materials. Part II. Denture base materials. J Oral Rehabili 7: 235-243.

46 Wong DM, Cheng LY, Chow TW (1999) Effect of processing method on the dimensional accuracy and water sorption of acrylic resin dentures. J Prosthet Dent 81: 300-304.

47 Elahi JM, Abdullah MA (1994) Effect of different polymerization techniques on dimensional stability of record bases. J Prosthet Dent 71: $150-153$

48 Smith BGN, Wright PS, Brown D (1994) The clinical handling of dental materials. ( $2^{\text {nd }}$ edn) Oxford, Wright, The University of Michigan, United States. p: 263.

49 Chen JC, Lacefield WR, Castleberry DJ (1988) Effect of denture thickness and curing cycle on the dimensional stability of acrylic resin denture bases. Dent Mater J 4: 20-24.

50 Yeung KC, Chow TW, Clark RKF (1995) Temperature and dimensional changes in the two-stage processing technique for complete dentures. J Dent 23: 245-253.

51 Mason HJ (1964) Extreme warpage of resin dentures in routine grinding and polishing. North West Dent 43: 97-
52 Phillips RW: (1973) Skinner's Science of Dental Materials. (7th edn) Philadelphia and Saunders WB Co. p: 99.

53 Lorton L, Phillips RW (1979) Heat-released stress in acrylic dentures. J Prosthet Dent 42: 23-26.

54 Pryor WJ (1943) Internal stresses in denture base materials. JADA 30: 1382

55 Skinner EW, Cooper EN (1943) Physical properties of denture resins: part I: curing shrinkage and water sorption. J Am Dent Assoc 30: 1845-1852.

56 Ristic B, Carr L (1987) Water sorption by denture acrylic resin and consequent changes in vertical dimension. J Prosthet Dent 58: 689693.

57 Duymus ZY, Yanikoglu ND (2004) Influence of a Thickness and Processing Method on the Linear Dimensional Change and Water Sorption of Denture Base Resin. Dent Mater J 23: 8-13.

58 Becker CM, Smith DE, Nicholls JI (1977) The comparison of denturebase processing techniques. Part I. Material characteristics. J Prosthet Dent 37: 330-338.

59 Woelfel JB, Paffenbarger GC (1959) Dimensional changes occuring in artificial dentures. Int Dent J 9: 451-460.

60 Sadamori S, Ganefiyanti T, Hamada T (1994) Influence of thickness and location on the residual monomer content of denture base cured by three processing methods. J Prosthet Dent 72: 19-22. 